\title{
Aeroacoustics Analysis of Globe Control Valves
}

\author{
A. S. Prakash, K. S. Ram and V. R. Kishore* \\ Department of Mechanical Engineering, Amrita School of Engineering, Coimbatore, \\ Amrita Vishwa Vidyapeetham, India. \\ *Email: v_ratnakishore@cb.amrita.edu \\ Phone: +91-8122957821; Fax: +91-4222656274
}

\begin{abstract}
Flow-induced noise in control valves is one of the greatest challenges faced by several industries and commonly used flow control device in process industries is globe control valves (GCV). In the present work numerical analysis was performed to study aeroacoustics of globe control valve. Axisymmetric globe control valve $(2.54 \mathrm{~cm})$ was analysed numerically using 2D large eddy simulation (LES) turbulence model for different valve openings. The Ffowcs-Williams and Hawkings (FWH) model was used to model the aero-acoustic. The fluid medium in the valve is air. It was observed that the sound pressure level (SPL) decreases with increase in the opening of the valve. The modification in the design of the control valve was considered to reduce SPL without affecting the inherent characteristic, flow coefficient $\left(\mathrm{C}_{\mathrm{v}}\right)$. The design modifications in the control valve considered were chamfering the seat and filleting the plug of the valve. Out of these modifications, the $20^{\circ}$ chamfer to the inlet side of seat gave the least sound pressure level for the various openings of the globe control valve.
\end{abstract}

Keywords: Globe control valves; aeroacoustics; computational fluid dynamics.

\section{INTRODUCTION}

Valves are commonly used components, found virtually in all process industries, where fluid flow control is of great importance. Valves vary widely in form and mode of application. Valves can be classified into some basic types like ball, butterfly, gate, globe and poppet. Globe valves are generally the preferred type for applications requiring frequent throttling and control of fluid flow. Due to this frequent operation and nature of flow in globe valve, aerodynamic noise is inevitable. Exposure to noise above $90 \mathrm{~dB}$ for long durations has been proved to affect the gross productivity of humans and may affect their hearing capability. The Environment Protection Act, 1986 notified by Ministry of Environment and Forests, Government of India states that the maximum allowable noise standards at industrial areas have been restricted to $75 \mathrm{~dB}$ within an area not less than $100 \mathrm{mts}$ [1]. Hence, there is a great need to understand the nature of aerodynamic noise that is generated in globe valves.

Most of the analysis, both experimental and computational for control valves in general, and globe valves, in particular, was about predicting flow patterns [2-6], cavitation [7-11] and flow coefficient [12, 13]. Davis and Stewart [4] have modelled three-dimensional plug type globe valves using a simplified 2D axisymmetric flow model. They used the same model for validating the flow coefficient of the valve. The numerically determined flow coefficient $C_{v}$ using this model matched well with the experimentally measured $C_{v}$ in the range 2.5 to 13. Davis and Stewart [5] have also 
performed a detailed experimental study to understand that for the plug type globe control valve, the flow field is close to axisymmetric. Using pressure and flow fields, they found that for most of the plug travel, flow is predominantly axisymmetric.

Salvador et al. [14] studied cavitation in plug type globe control valves using a 2D axisymmetric model near the plug seat region. Young et al. [15] studied 3D flow through LNG Marine Control Valves for their advanced design using numerical analysis. Yang et al. [16] studied flow patterns and flow coefficients using 3D numerical simulations. Wang et.al [17] carried out simulations to predict the threedimensional flow fields in a large scale Gas Control Valve. Chern et al. [8] proposed a cavitation model for prediction of cavitation inside globe valves with and without a cage. Lafon [18] has analyzed the aerodynamic noise of cavity that houses the plug of the gate valve. They have modelled it using a 2D cavity.

Aeroacoustics involves the study of noise generated due to turbulent flow and flow-induced vortex shedding. Numerous models are available for modelling turbulent flow like two-equation models (RANS), Large Eddy Simulation (LES), Direct Numerical Simulation (DNS) [19] studied the effect of turbulence model on the prediction of aerodynamic noise in the subsonic cavity. This model considered was the standard benchmark case reported in Fourth Computational Aero-Acoustics (CAA) Workshop on Benchmark Problems. The different turbulence models considered were URANS k- $\omega$ SST, delayed DES and SAS. DDES showed the better prediction of cavity sound pressure level up to $5000 \mathrm{~Hz}$ with respect of experimental results. This is mainly because DDES was able to predict properly the small-scale structures due to turbulence. Several researchers have used Large Eddy Simulation (LES) to study aeroacoustics in the cavity [18, 20-22]. Hence, it is essential to use scale resolved models like LES to predict aeroacoustics.

Most of the research work on control valves to date were on predicting flow features in the control valve, flow coefficients and cavitation. To the best of knowledge of authors, the aeroacoustics of globe control valves have not been studied. The present work details the aeroacoustic analysis of a simplified 2D, axisymmetric plug type globe control valve for different plug openings namely 30, 50 and 70\% using LES for modelling turbulence. The commercial code FLUENT was the software used. Further, modifications were carried out to the valve to reduce the aeroacoustic noise, and the results are presented.

\section{NUMERICAL MODEL}

\section{Governing Equations}

Based on the literature [18-22], scale resolved modelling for turbulence is essential for aeroacoustics modelling. In the present work, turbulence is modelled using LES model with Smagorinsky-Lilly subgrid model. The filtering equations for continuity and the Navier-Stokes [23] are given in Eq. (1) and (2).

$$
\begin{aligned}
& \frac{\partial \rho}{\partial t}+\frac{\partial}{\partial x_{i}}\left(\rho \bar{u}_{i}\right)=0 \\
& \frac{\partial}{\partial t}\left(\rho \bar{u}_{i}\right)+\frac{\partial}{\partial x_{j}}\left(\rho \bar{u}_{i} \bar{u}_{j}\right)=\frac{\partial}{\partial x_{j}}\left(\sigma_{i j}\right)-\frac{\partial p}{\partial x_{i}}-\frac{\partial \tau_{i_{j}}}{\partial x_{j}}
\end{aligned}
$$


where $\sigma_{i j}$ is the stress tensor due to molecular viscosity and $\tau_{i j}$ is the subgrid-scale stress. The eddy-viscosity is modelled by Smagorinsky-Lilly model in Eq. (3).

$\mu_{\mathrm{t}}=\rho \mathrm{L}_{\mathrm{s}}^{2}|\overline{\mathrm{S}}|$

where $L_{s}$ is the mixing length for subgrid model.

\section{Acoustic Simulation}

The aero acoustic noise was modelled in the present work using Ffowcs-Williams and Hawkings equation [23] which is given in Eq. (4).

$$
\begin{aligned}
& \frac{1}{\mathrm{c}_{\mathrm{o}}^{2}} \frac{\partial^{2} \mathrm{p}^{\prime}}{\partial \mathrm{t}^{2}}-\nabla^{2} \mathrm{p}^{\prime}=\frac{\partial^{2}}{\partial \mathrm{x}_{\mathrm{i}} \partial \mathrm{x}_{\mathrm{j}}}\left\{\mathrm{T}_{\mathrm{ij}} \mathrm{H}(\mathrm{f})\right\}-\frac{\partial}{\partial \mathrm{x}_{\mathrm{i}}}\left\{\left[\mathrm{P}_{\mathrm{ij}} \mathrm{n}_{\mathrm{j}}+\rho \mathrm{u}_{\mathrm{i}}\left(\mathrm{u}_{\mathrm{n}}-\mathrm{v}_{\mathrm{n}}\right) \delta(\mathrm{f})\right]\right\}+\frac{\partial}{\partial \mathrm{t}}\left\{\left[\rho_{\mathrm{o}} \mathrm{v}_{\mathrm{n}}+\rho\left(\mathrm{u}_{\mathrm{n}}-\right.\right.\right. \\
& \left.\left.\left.\mathrm{v}_{\mathrm{n}}\right)\right] \delta(\mathrm{f})\right\}
\end{aligned}
$$

where $p^{\prime}$ is the far field acoustic pressure and the mathematical surface of the body is represented by $f$. Fine computational grid at every grid point is required to solve $\mathrm{FW}-\mathrm{H}$ equation which is computationally very expensive. However, generalised function theory and free Greens function can be used to get the solution at receiver locations.

\section{Computational Domain}

The cross-section of a standard globe control valve is normally identified by three sections. The first region is the inlet region. The second one is a two-dimensional plug and seat region. The third one is the exit region (Refer with Fig.1). The initial design of globe control valve used in this work is the same as that of Davis and Stewart [4].

The diameter (D) of the domain was set to $2.54 \mathrm{~cm}$. The plug seat region was axi-symmetric along the horizontal and vertical axes. The valve was modelled with the plug positioned at different openings. The mesh was coarsened towards inlet side and towards the exit side while it was fine towards the two-dimensional plug seat region. The entire domain spanned 6D from the leading side to the seat and 10D from the seat to the trailing edge.

Pressure monitors were placed along the upstream and downstream sections of the globe control valve. These were placed at about along the radius $1 \mathrm{D}$ and 2D upstream and downstream of the plug seat section. Based on the results, SPL values from all the pressure monitors were showing similar trend and hence we chose 1D downstream pressure monitor to comparing results various valve modifications. The two of those monitor points are shown in Figure 1. 


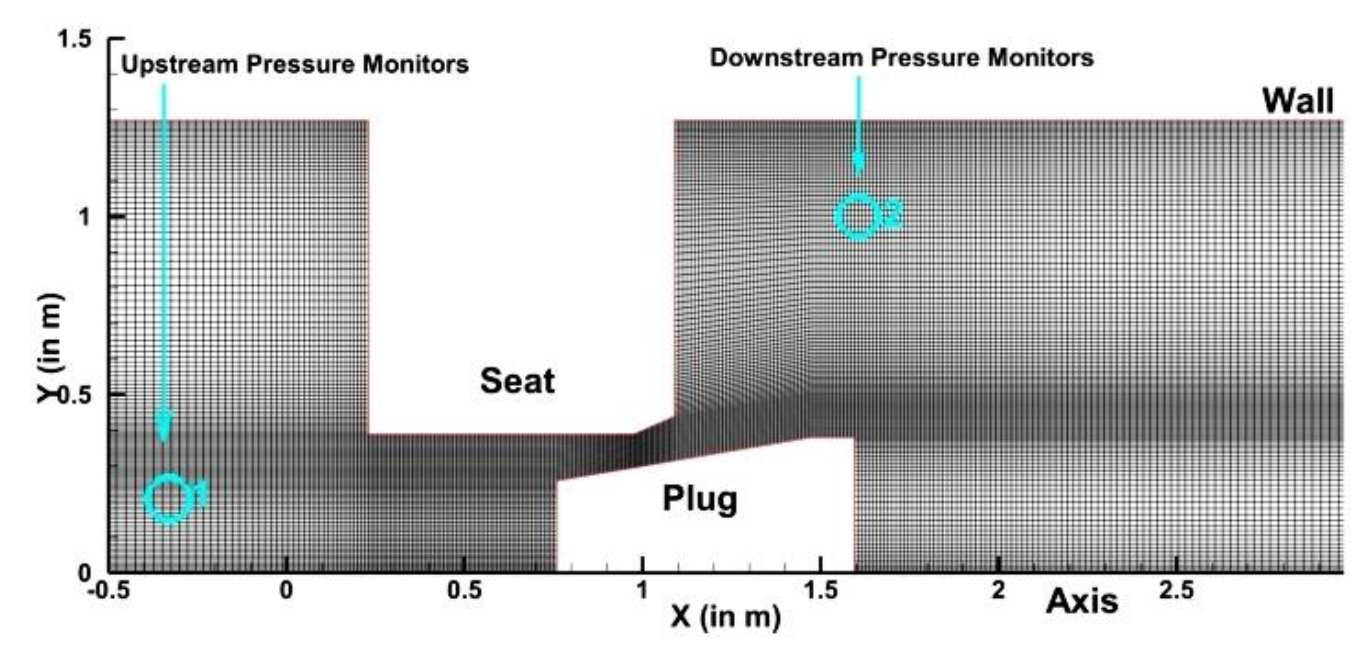

Figure 1. Computational grid.

\section{Grid Details}

A two-dimensional axisymmetric domain was considered in the study with the plug seat domain meshed finely in GAMBIT. The grid used in the study was structured. After a preliminary investigation for grid independence based on validation case (grid was carefully chosen such that the valve plug and seat region was having grid size is smaller than that of fine grid validation case), for all three cases with different valve openings; grids greater than 150,000 cell volumes were meshed and clustered in the plug seat regions; since logically this was the area of largest flow gradients.

\section{Boundary Conditions}

The model was assumed to be axisymmetric as the flow is axisymmetric according to experimental study of Davis et al [4]. The boundaries were considered to be solid including the plug, seat and top wall which were represented using no-slip velocity boundary conditions. Axis boundary conditions were applied across the centre line. The inlet was represented using mass flow inlet boundary condition since air was assumed to be compressible ideal gas. Davis and Stewart [4] conducted an experimental study on $2.54 \mathrm{~cm}$ globe control valve to find the flow coefficient $C_{v}$. The obtained value of rated $\mathrm{C}_{\mathrm{v}}\left(\mathrm{C}_{\mathrm{v}}\right.$ value at $100 \%$ opening) of the globe control valve under study (Valve A: 2.54 $\mathrm{cm}$ valve with seat radius $0.471 \mathrm{~cm})$ was 2.5 . Flow coefficient $\left(\mathrm{C}_{\mathrm{v}}\right)$ as per ISA standard $\mathrm{S} 7501,[2]$ is the number of gallons of water per minute that can flow through the valve with a pressure drop $(\Delta \mathrm{P})$ of $1 \mathrm{psi}$.

\section{Computational Methodology}

A general-purpose CFD code, Fluent 13.0 was used for solving the governing equations of mass, momentum and turbulence for unsteady flow. Parallel computations were carried out to reduce the computational time. Air was modelled as the ideal gas. The convergence criteria for the residuals were set to $10^{-6}$ for all the equations. The time step size for all cases was set to $10^{-6}$ and was iterated for 0.1 million time steps. Second order upwind scheme was used to discretise convective terms of all the governing equations, and fractional step algorithm is used for pressure-velocity coupling. The 
solution was allowed to converge at every time step till the convergence criteria were satisfied.

\section{VALIDATION OF NUMERICAL MODEL}

In the present globe valve, the phenomenon identified was similar to that described by Rockwell et al. on the behaviour of 2D, axisymmetric cavities. The noise generated was due to the cavity that houses the disc of the gate valve [18]. So the validation of computational aeroacoustics of low Mach number flow in a cavity using Large Eddy Simulation turbulence model was carried out initially.

The aero acoustics phenomenon occurring in globe control valve was similar the noise generated due to the cavity that houses the disc of the gate valve [18]. So the present numerical model was validated against the experimental results of a partially open shallow cavity by Lafon et al. [18].

A partially open shallow cavity problem was studied experimentally and numerically by Lafon [18] is shown in Figure 2 (a). In the cavity noise problem, the maximum velocity (V) was considered as the nominal velocity. The characteristic dimensions of the cavity are in Figure 2 (a): $d=0.05 \mathrm{~m}, \mathrm{~h}=0.02 \mathrm{~m}, \mathrm{H}=0.137 \mathrm{~m}, \mathrm{~L}=$ $0.073 \mathrm{~m}$. The same was taken for validation. A structured mesh was created for the same, with 391034 grids and was finely meshed towards the cavity mouth with a pressure monitor at the bottom of the cavity as shown in Figure 2 (b). The interval size of the edge mesh at the cavity bottom was set to be $0.01 \mathrm{~mm}$. The time step was set to $10^{-6}$ seconds.

Figure 3 shows the sound pressure level plot for various frequencies. The first peak frequency is at $1026.7 \mathrm{~Hz}$ and magnitude is $137.2 \mathrm{~dB}$. This is close to the experimental value obtained by Lafon et al. [18] which is of magnitude $128 \mathrm{~dB}$ at 1199 $\mathrm{Hz}$.

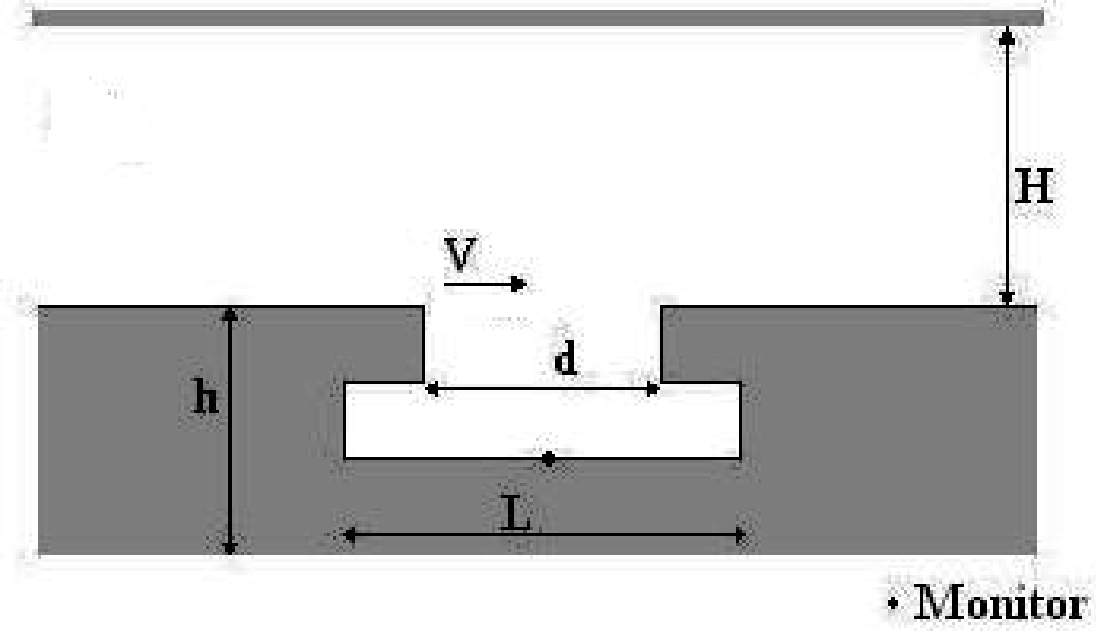

(a) 


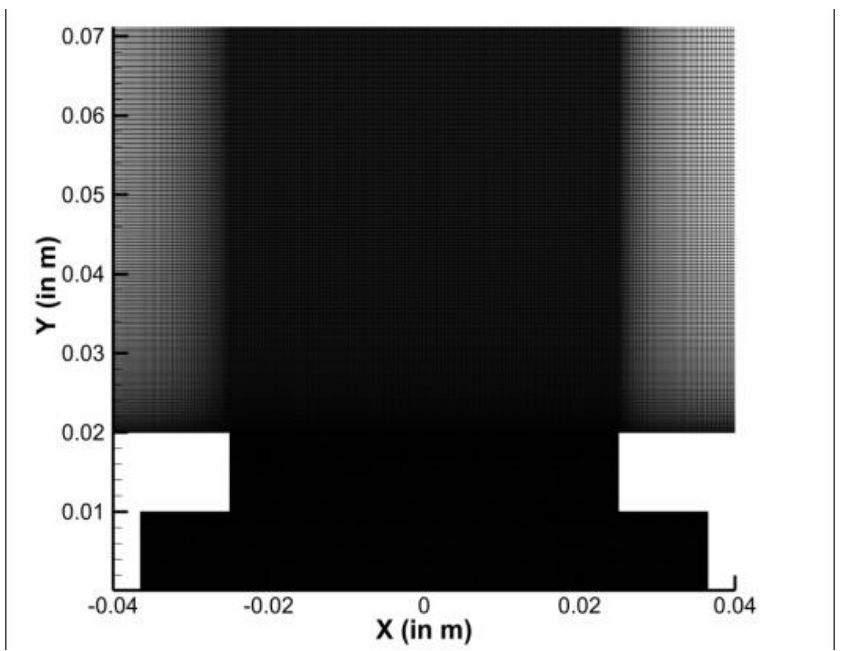

(b)

Figure 2. (a) The cavity studied and; (b) structured mesh of cavity

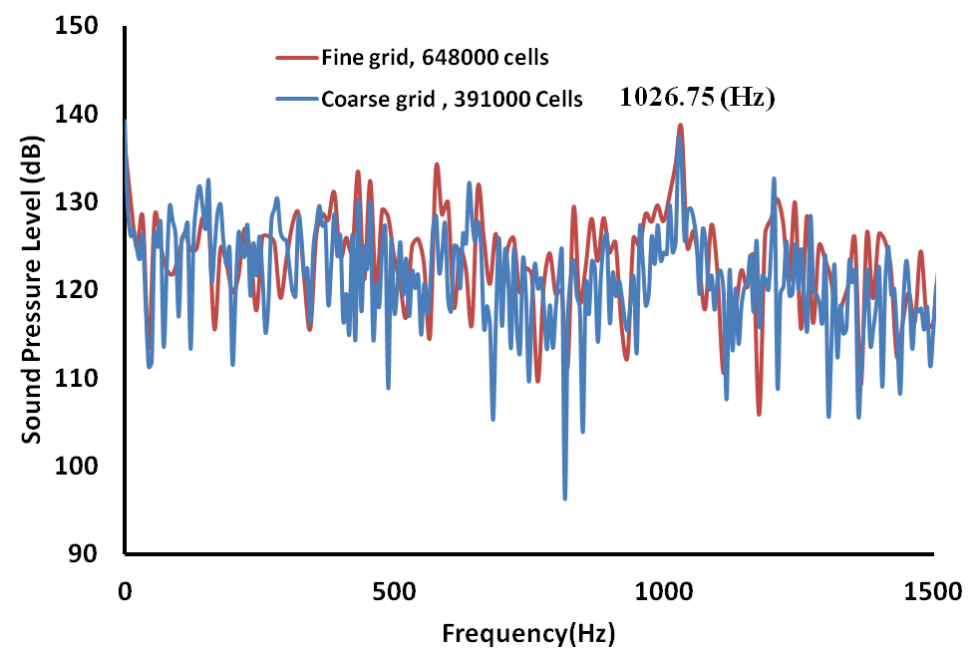

Figure 3. Computed sound pressure level for various frequencies at the monitor point.

\section{RESULTS AND DISCUSSION}

The simulations were performed for $30 \%, 50 \%$ and $70 \%$ openings of the globe control valve. First, the standard design was studied to identify the peak SPL levels. Further, the design was modified at the inlet plug region and later the inlet seat region. A fillet radius was provided at the inlet region, and the entire domain meshed with quadrilateral elements. These design modifications were such that the orifice area between seat and plug remains unchanged and hence the $C_{v}$ of the valve remains almost constant.

\section{Initial Design}

The initial design of axi-symmetric plug type globe control valve taken was the same as that specified by Davis and Stewart [4]. The different openings considered of the globe control valve were $30 \%, 50 \%$ and $70 \%$. The SPL for various valve openings at 1D upstream and downstream monitor points are shown in Figure 4. From the figure, it is 
clear that as the valve opening increases the SPL decreases at both the monitor points. The reduction in SPL is more from $30 \%$ to $50 \%$ opening than from $50 \%$ to $70 \%$ opening.

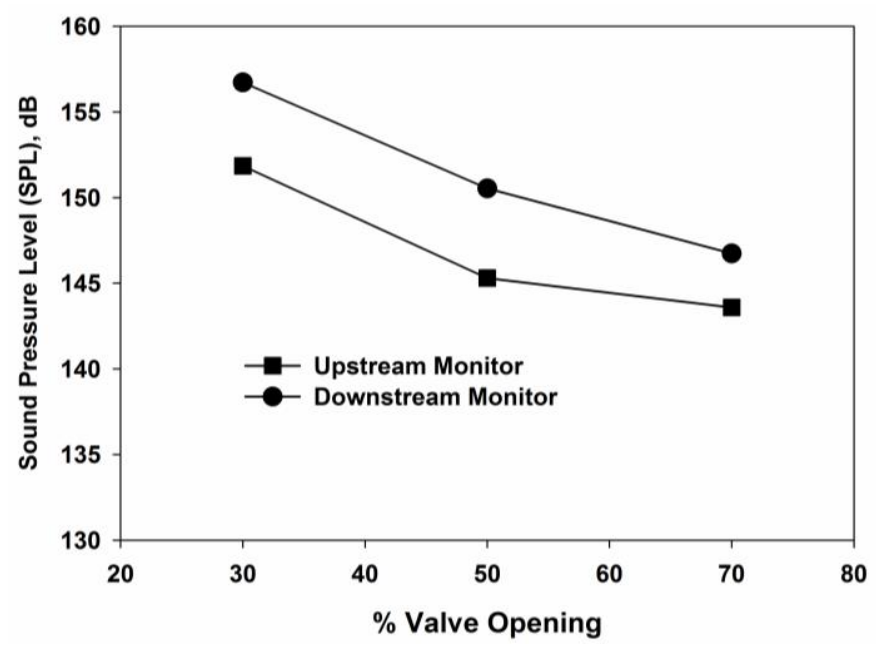

Figure 4. Sound pressure level at 1D upstream and downstream points for various valve openings.

The production of aeroacoustic noise was attributed to the occurrence of vortex shredding $[18,20,21]$. To understand the nature of vortex shredding the initial design at $50 \%$ opening has been studied in detail. The contours of vorticity magnitude were presented at a time interval of 0.00005 seconds as shown in Figure 5. The downstream monitor point is indicated as a black dot for clarity in Figure 5. It can be seen in all these figures that vortices are generated at upstream edge and downstream edge of seat and upstream edge of the plug. The vortex generated at the upstream edge of the seat hits the seat wall and generate shear layer which initiates the vortex generated at the downstream edge of the seat. The vortices generated at the downstream edge (or outlet side) of the seat and plug mix with each other. The vortex shredding frequency from the plug and seat are different.

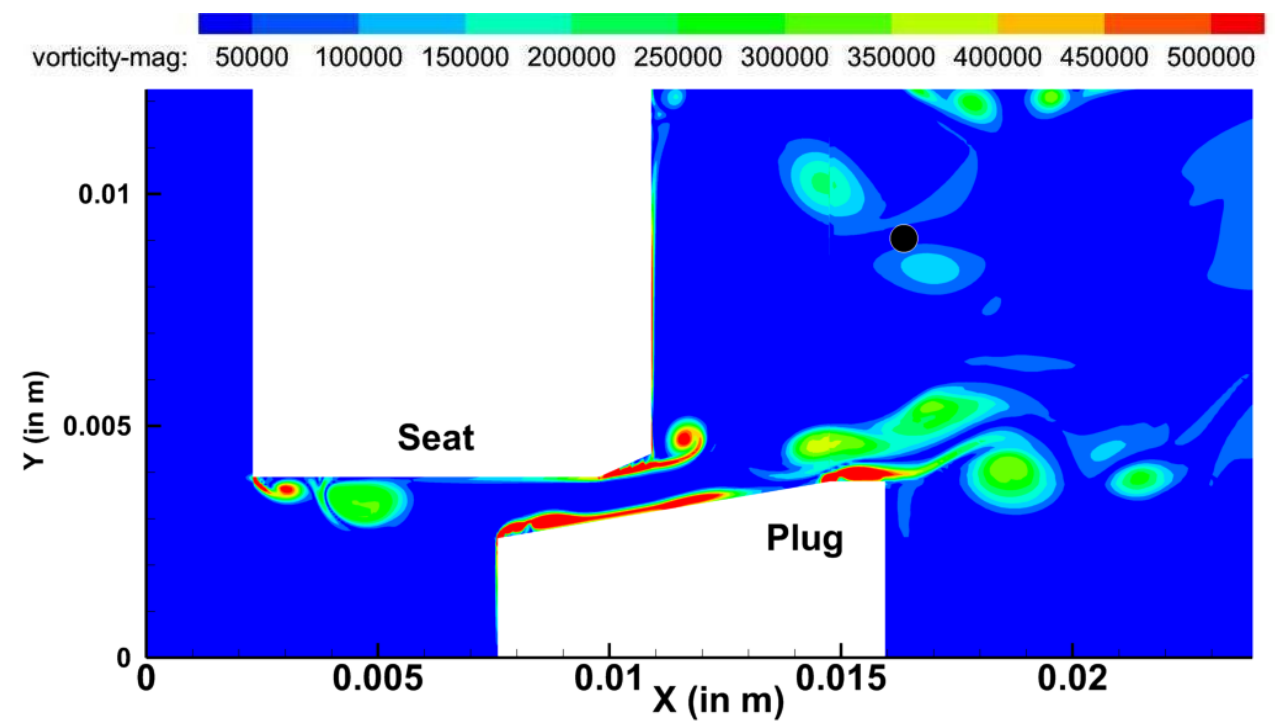

(a) 


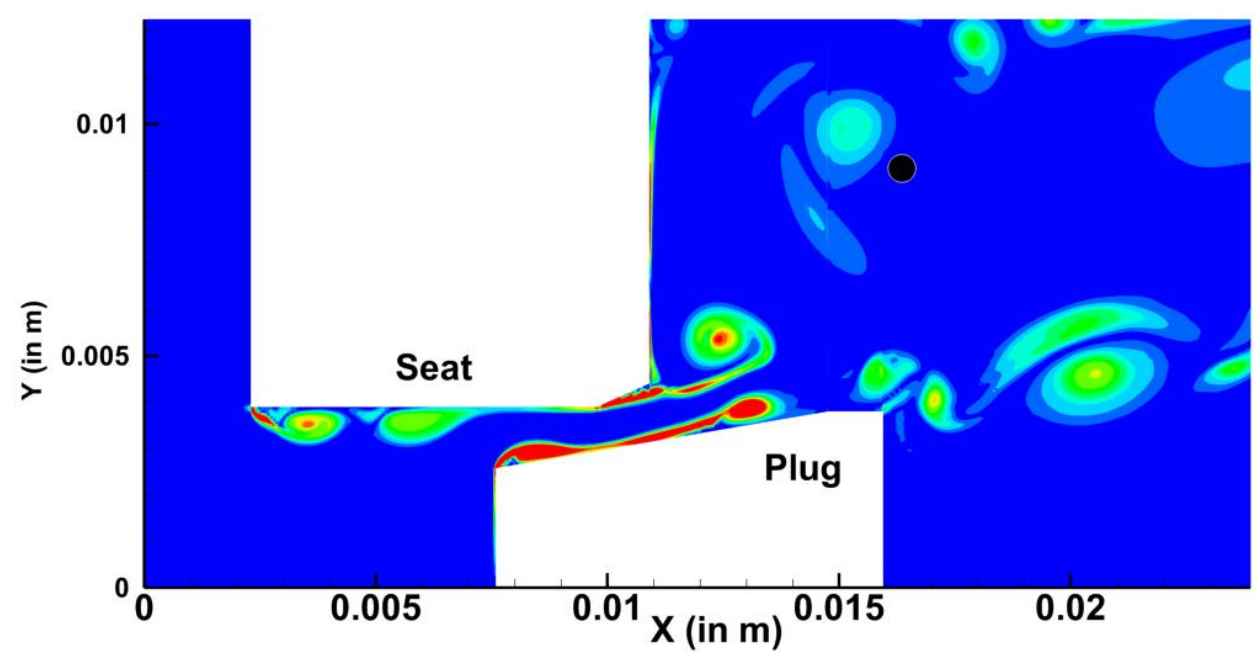

(b)

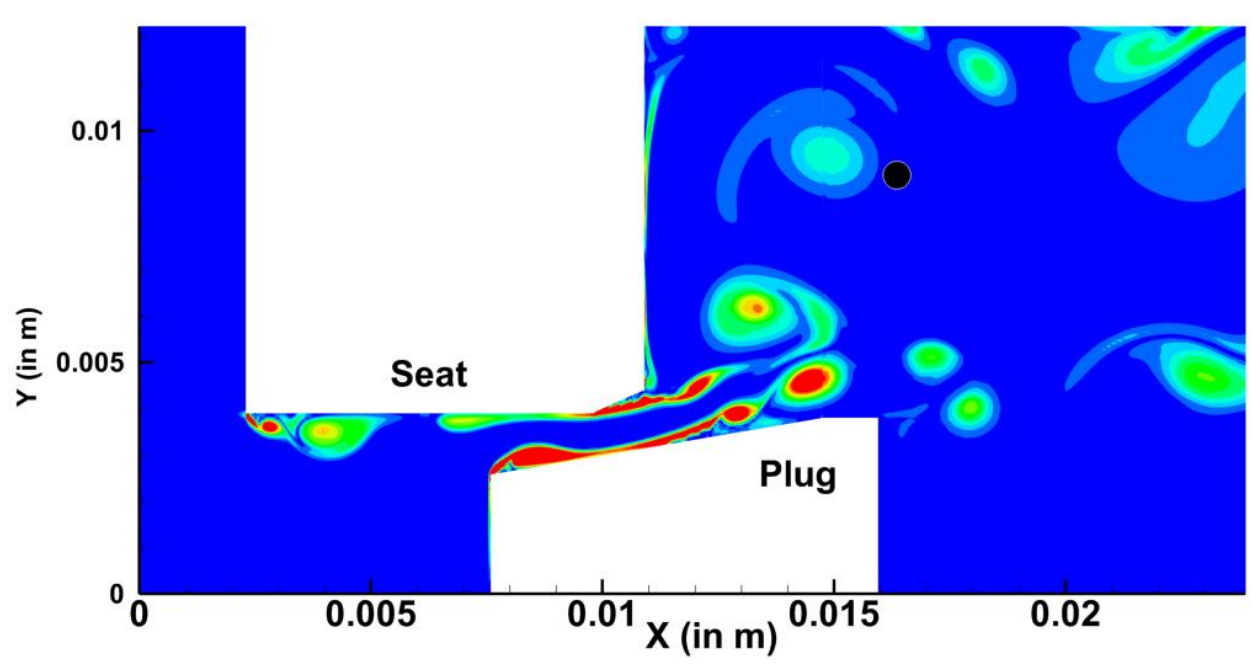

(c)

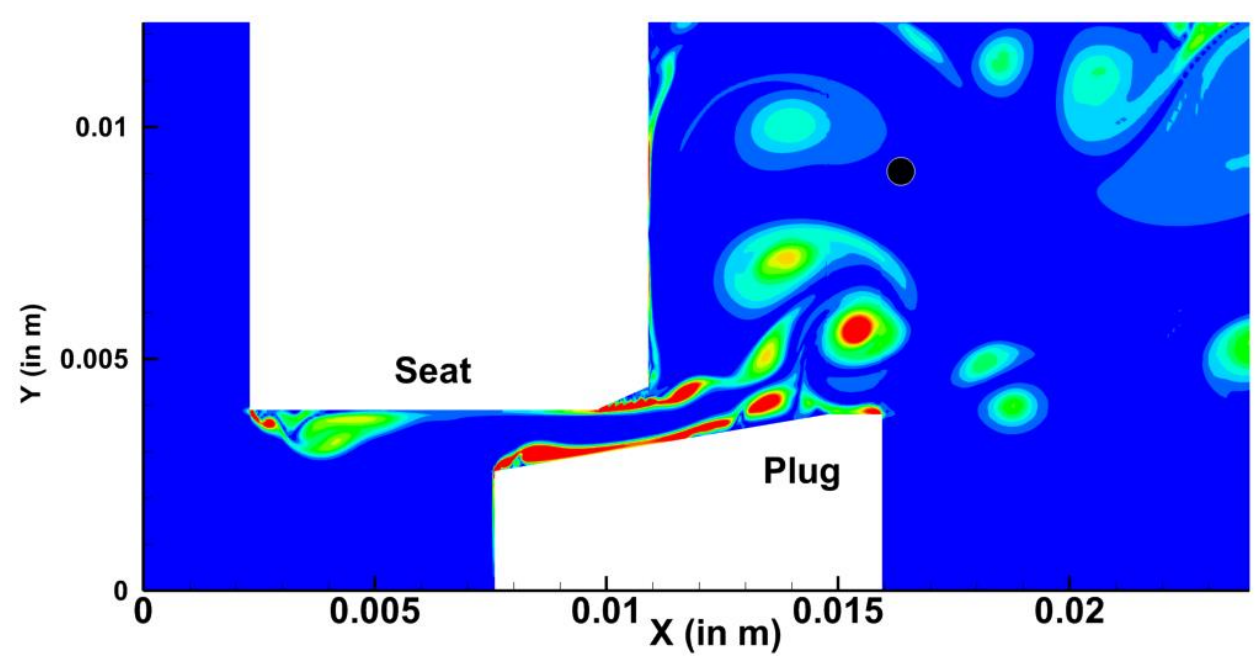

(d)

Figure 5. Vortex shredding cycle at $50 \%$ opening. 
Figure 6 (a), (b) and (c) shows the vorticity magnitude contours at three different valve openings. The intermingling of vortices generated from seat and plug is more for $30 \%$ compared to 50 and $70 \%$ openings. This is due to an increase in the minimum orifice area.

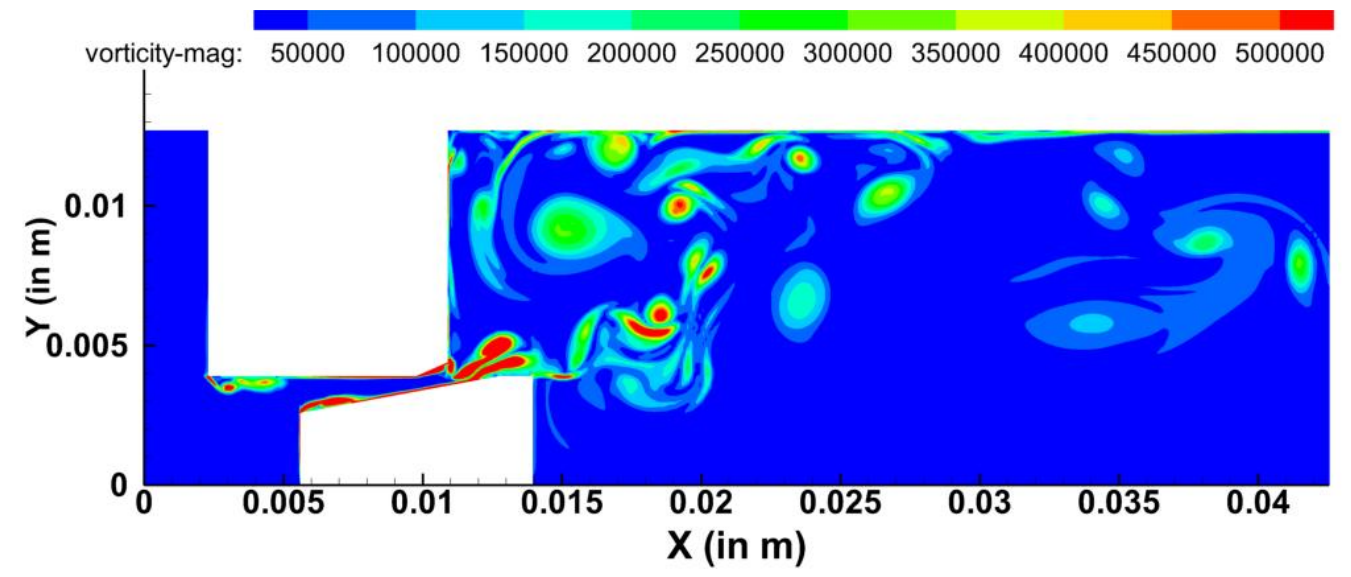

(a)

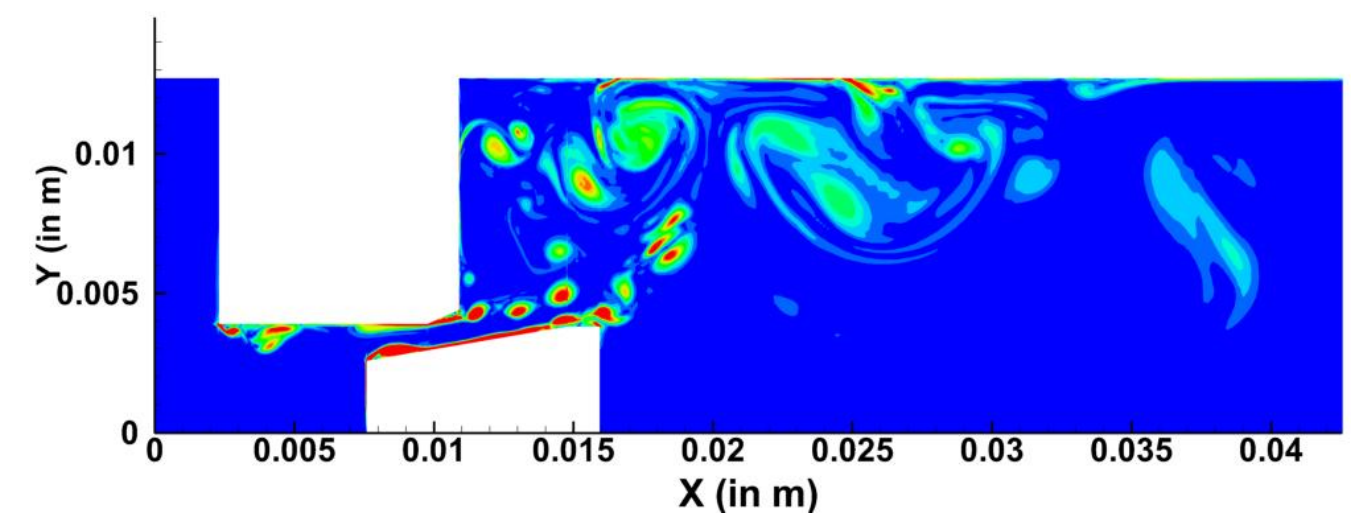

(b)

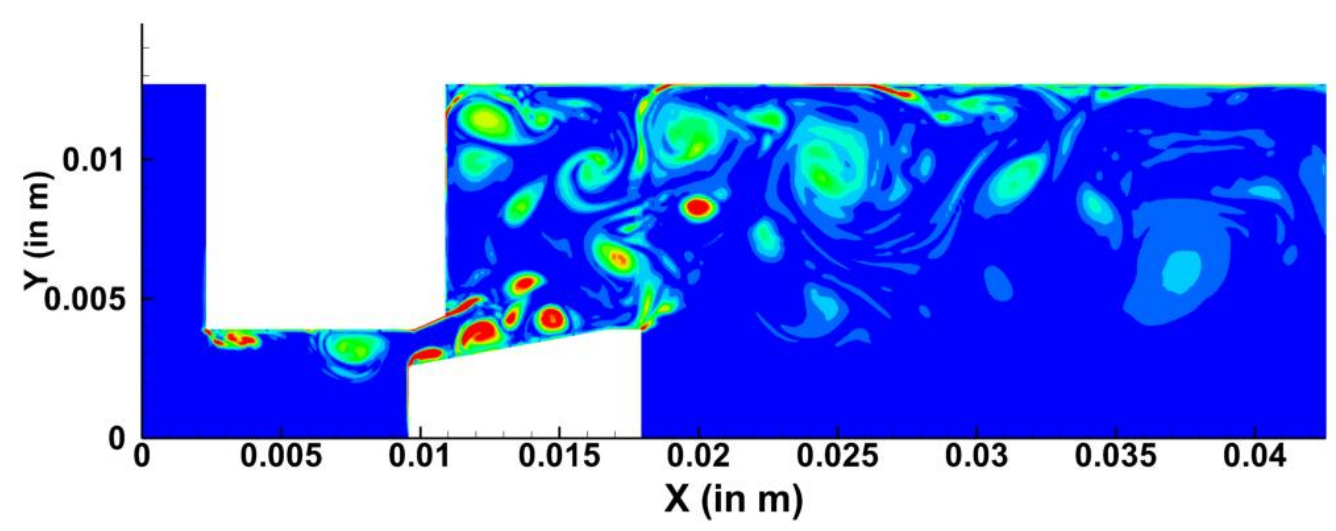

(c)

Figure 6. Vorticity magnitude contours at different valve openings of GCV (a) $30 \%$, (b) $50 \%$ and; (c) $70 \%$ opening 


\section{Design Modifications for Plug and Seat Geometry}

The standard design was modified to reduce aerodynamic noise. The modifications were done for plug and seat such that $C_{v}$ remains almost constant. The seat was modified with chamfers of $20^{\circ}, 30^{\circ}$ and $45^{\circ}$ at the inlet side as shown in Figure 7 . The plug was modified with a fillet on the inlet side. The effect of these modifications on SPL have been studied and presented in this section.

Figure 8 shows the SPL levels at upstream and downstream locations (1D) for various valve designs. The openings considered are 30\%, 50\% and $70 \%$ as in the case of standard design. The trends of sound pressure level (SPL) at upstream and downstream monitor points are similar. It is evident from the plots that for $30 \%$ opening all design modifications (chamfers on the seat and filleting on plug) cause a reduction in SPL when compared with the standard design. The reduction in SPL for the plug modified model is less compared to seat modified one. Also, all the three chamfer modifications were giving almost the same SPL for $30 \%$ opening. But as the valve opening increases to $50 \%$ and $70 \%$, the SPL shows an increasing trend for all the designs except for the case of the $20^{\circ}$ chamfer which shows a decreasing trend.

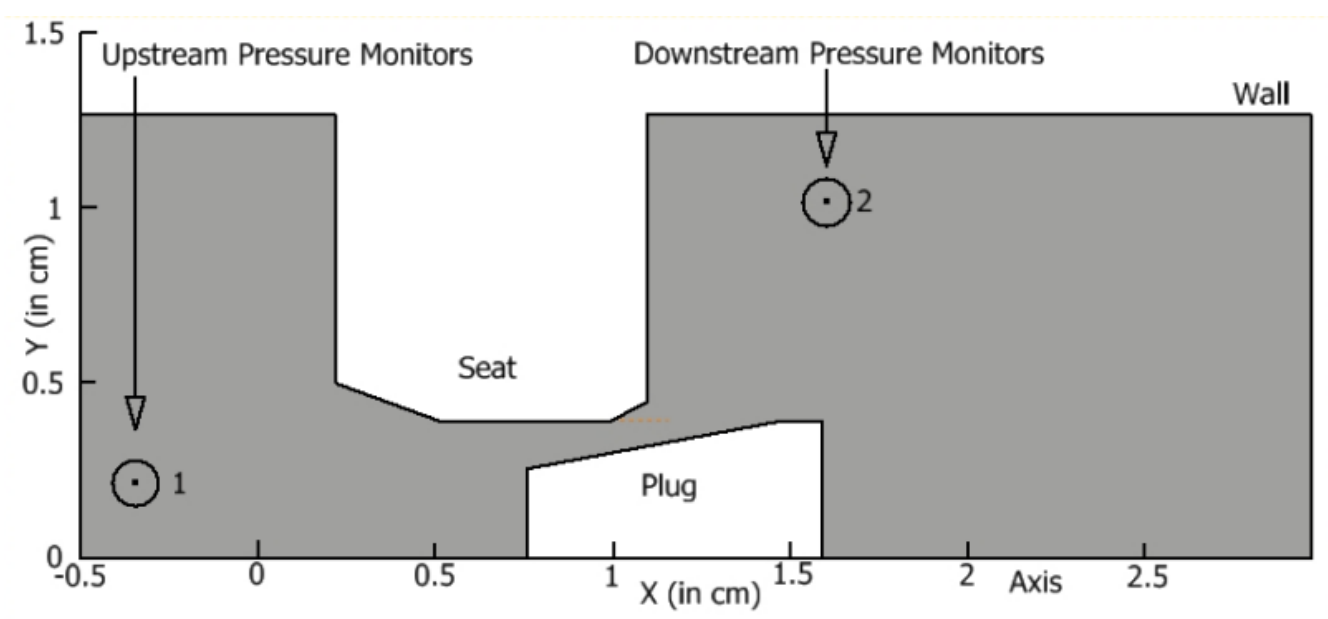

(a)

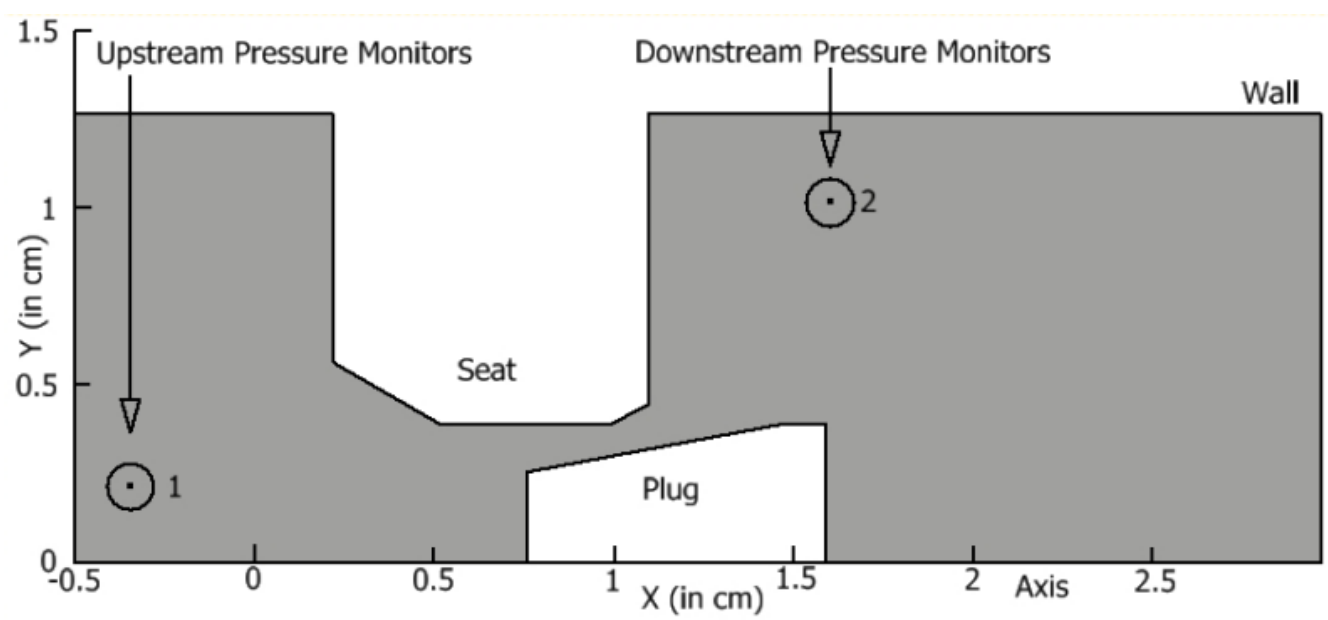

(b) 


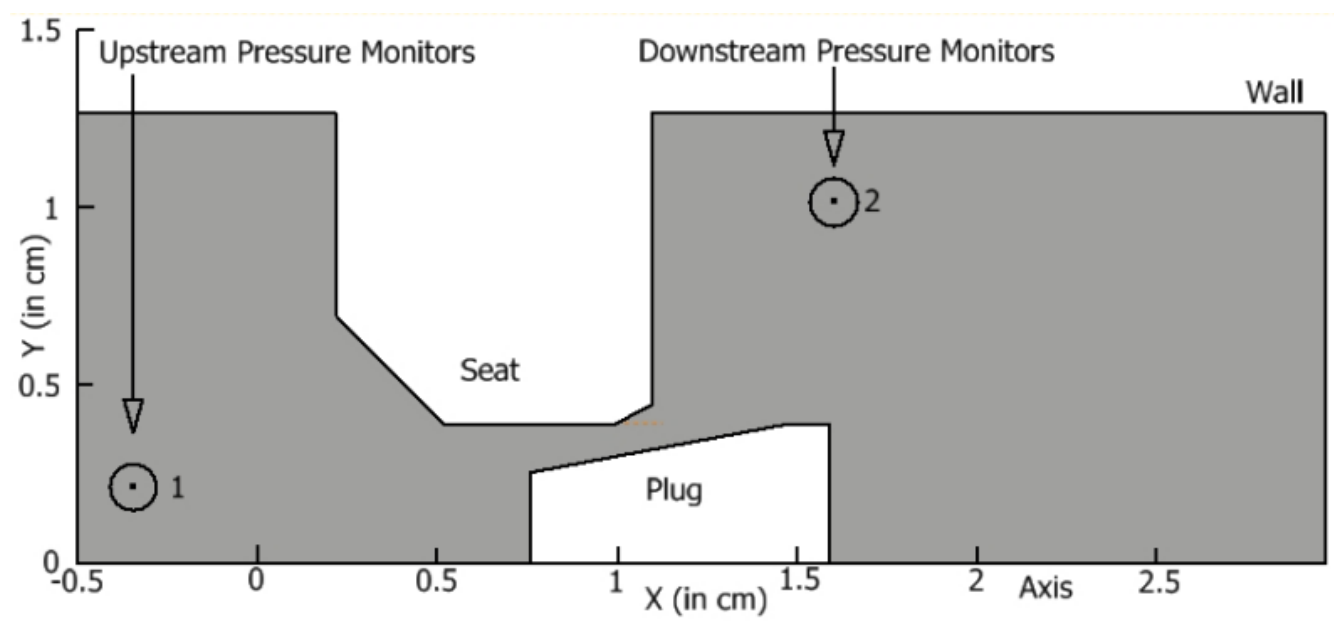

(c)

Figure 7. Design modification of valve seat with chamfer angle of (a) $20^{\circ}$ (b) $30^{\circ}$ and; (c) $45^{\circ}$.

In Figure 8(a) and 8(b), when a $20^{\circ}$ chamfer was introduced at the inlet side of the seat an appreciable reduction in SPL was noted in both the upstream and downstream sections. To understand the phenomenon of aeroacoustic noise for the design modifications, the vorticity magnitude contours were investigated.

Figure 9(a) to 9(e) shows the vorticity plots for initial design and modified designs for $30 \%$ opening. Figures are in the order of initial design, $20^{\circ}, 30^{\circ}, 45^{\circ}$ chamfer to the seat and fillet to plug. The black dots in the figures represent the pressure monitor point. It is clear from Figure 8(a) to 8(d) that the introduction of chamfer has eliminated the primary vortex formed at the inlet side of the seat. But the nature of the flow on the plug remains the same for all these cases. It can be seen that for all three chamfer designs, the overlap of plug and seat remains the same for $30 \%$ opening. The vortex that was generated at the inlet side of seat for chamfers cases subsides to form a shear layer when reaches a straight portion of the seat. For this reason, the SPL for all the chamfers cases for $30 \%$ opening is more or less the same value.

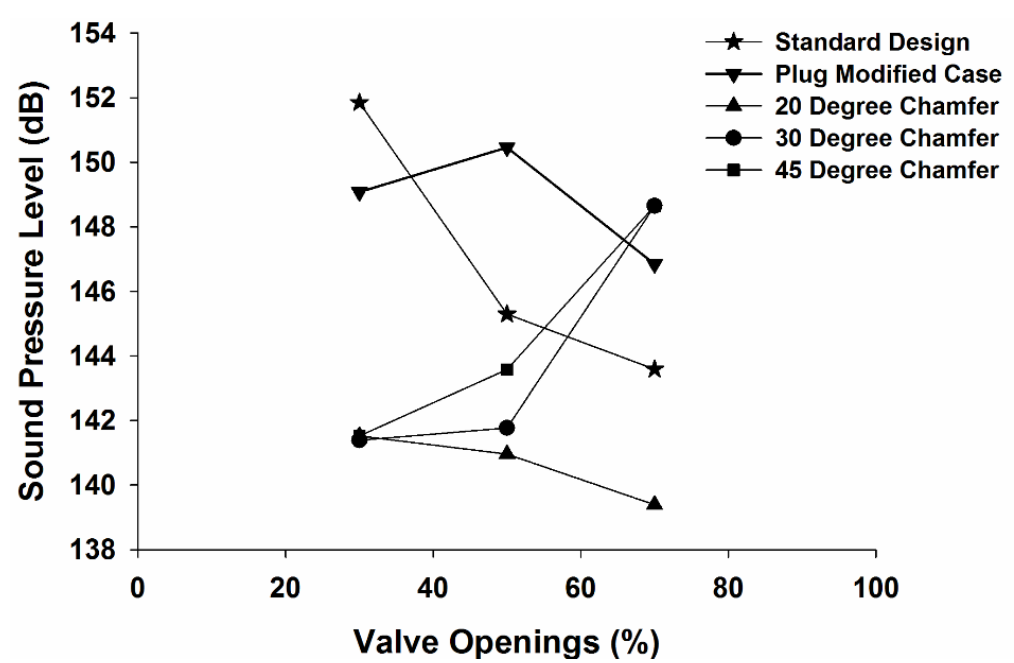

(a) 


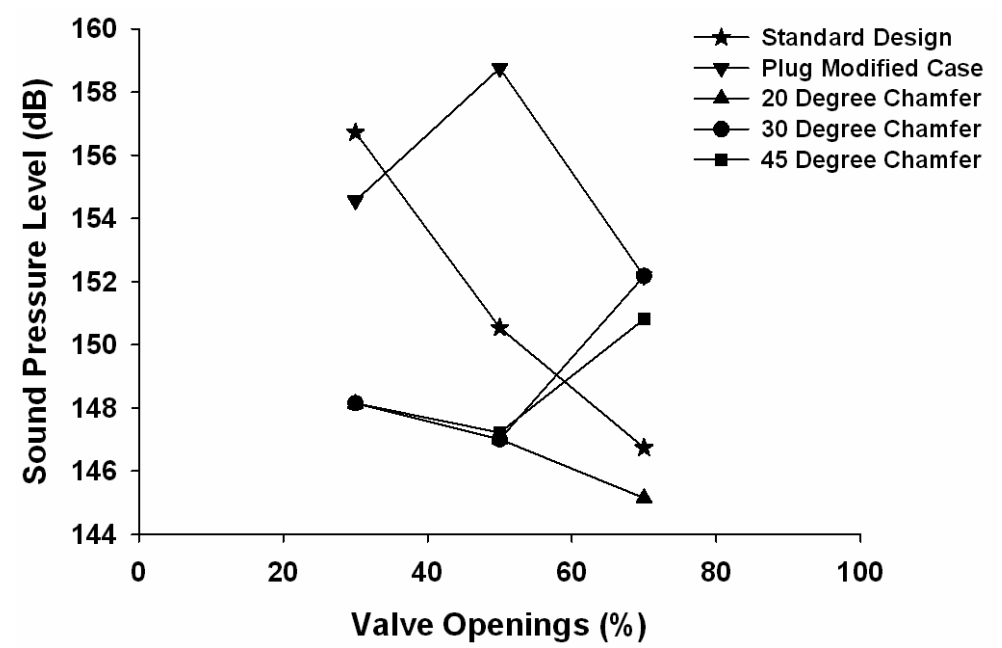

(b)

Figure 8. Sound pressure level (SPL) plots for modified designs at (a) upstream and;

(b) downstream monitor

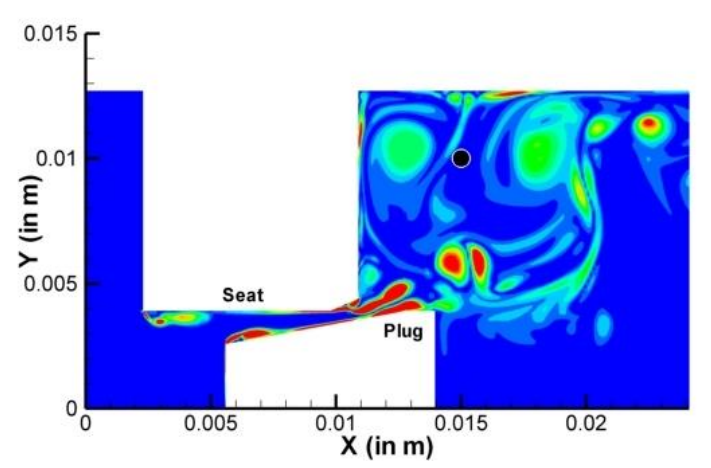

(a)

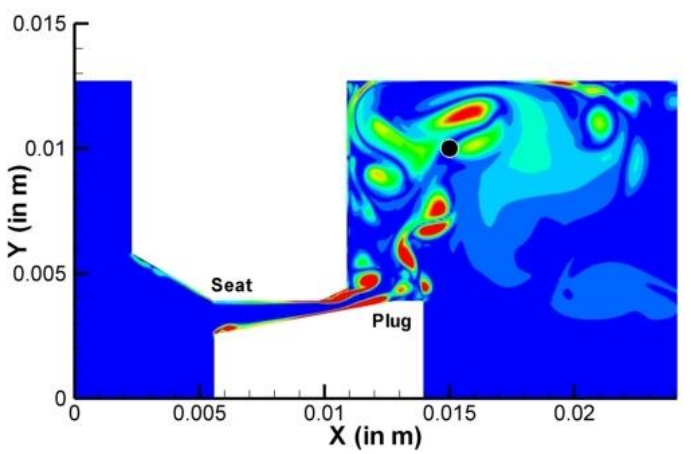

(c)

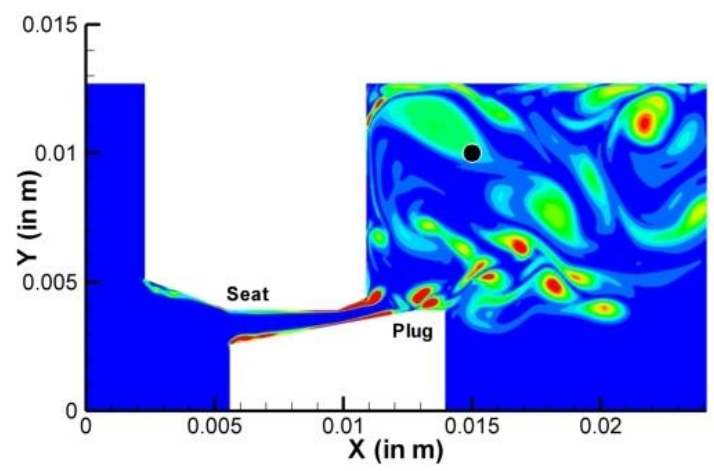

(b)

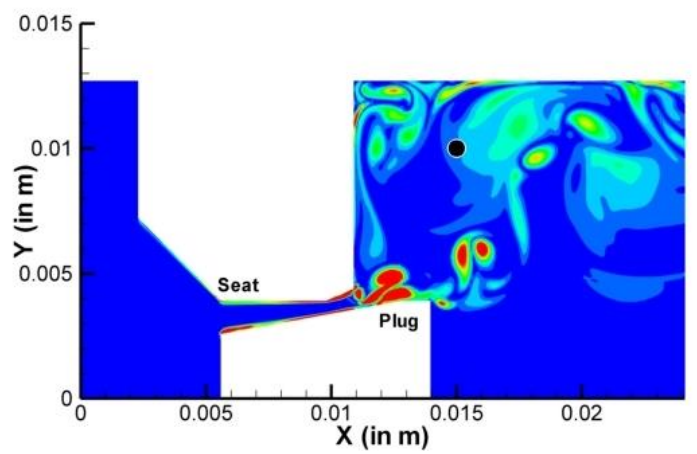

(d) 


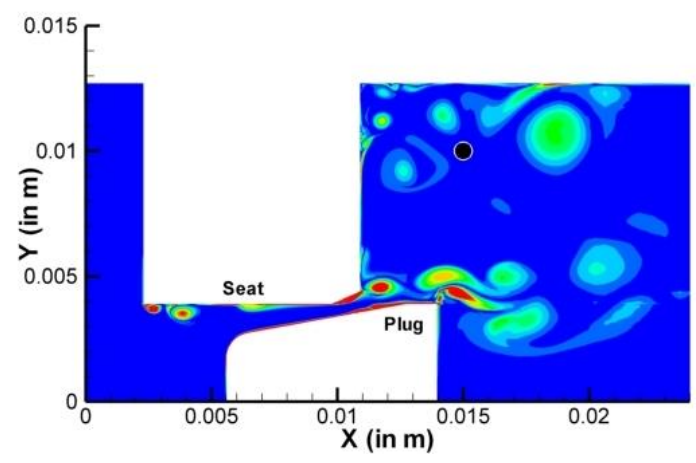

(e)

Figure 9. Vorticity magnitude plots of $30 \%$ opening in (a) initial design, and modified design at (b) $20^{\circ}$ (c) $30^{\circ}$ and; (d) $45^{\circ}$ chamfer, and (e) fillet to plug.

Figure 10 (a) to 10 (d) show vorticity magnitude contours of $30 \%$ and $70 \%$ openings with $20^{\circ}$ and $45^{\circ}$ chamfer angle. The $45^{\circ}$ chamfer gives a smaller straight edge on the seat. The shear layer forming at the seat for $45^{\circ}$ chamfer with $70 \%$ opening is causing more vortex shredding. This leads to a higher SPL for $45^{\circ}$ chamfer valve when compared to $20^{\circ}$ chamfer valve.

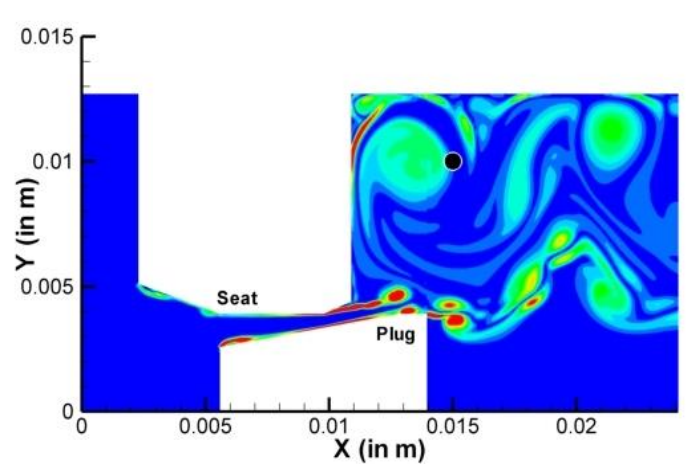

(a)

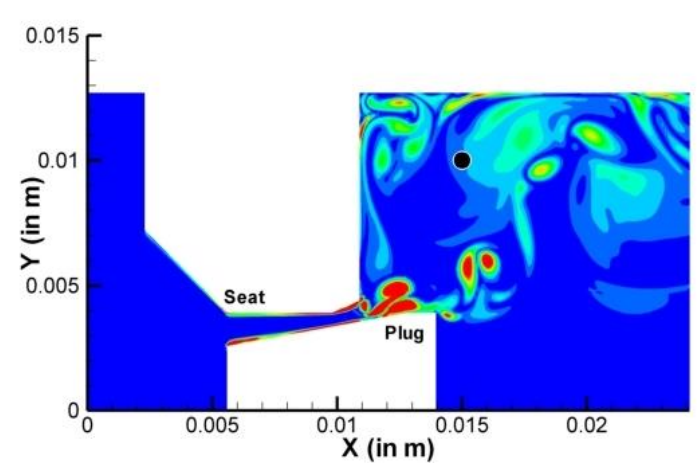

(c)

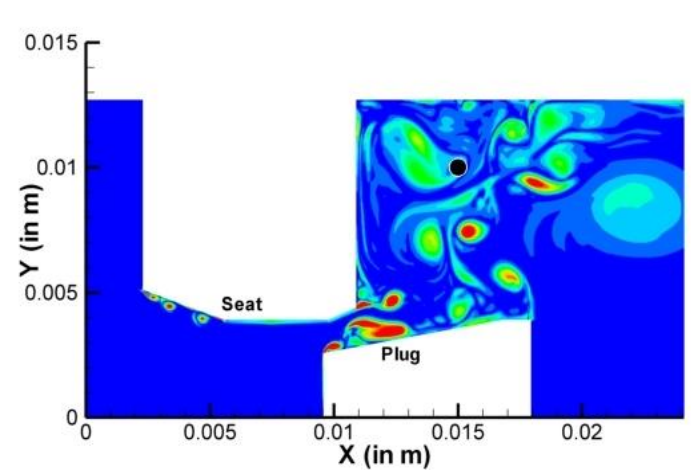

(b)

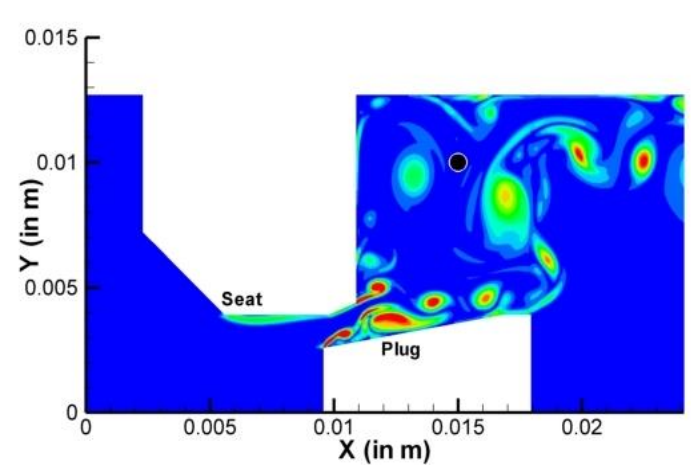

(d)

Figure 10 . Vorticity magnitude plots of modified designs with chamfer angle of (a) $20^{\circ}$ with $30 \%$ opening, (b) $20^{\circ}$ with $70 \%$ opening (c) $45^{\circ}$ with $30 \%$ opening and; (d) $45^{\circ}$ with $70 \%$ opening. 


\section{CONCLUSION}

The computational aeroacoustics study was performed for globe control valve using large eddy simulation (LES) turbulence model for different valve openings. The various conclusions obtained from the present work are:

i. the increase in the opening of the valve, the sound pressure level reduces, and this reduction is not linear.

ii. The aeroacoustics noise is mainly due to vortex shedding from seat and plug. The rate of vortex shedding from seat and plug are different. The intermingling of vortices generated from the seat and plug determines the sound pressure level.

iii. The $20^{\circ}, 30^{\circ}$ and $45^{\circ}$ the chamfer to the inlet of the seat reduced SPL for $30 \%$ opening relative to the standard design whereas for $20^{\circ}$ chamfer SPL reduced with higher valve openings. Also, modification to plug of the valve increase the SPL with reference to the standard design.

\section{REFERENCES}

[1] India Gov. Noise Pollution Norms. Ministry of Environment \& Forests, Paryawaran Bhawan, CGO Complex, Lodi Road, New Delhi, 110003 India: Ministry of Environment and Forests; 1986.

[2] Sreekala SK, Thirumalini S. Effect of cage configurations on flow characteristics of globe valves. World Journal of Engineering. 2016;13:61-5.

[3] Shin CH. A numerical study on the characteristics of transient flow in a pressure regulator resulting from closure of the pressure control valve. Journal of Mechanical Science and Technology. 2013;27:443-9.

[4] Davis JA, Stewart M. Predicting globe control valve performance-part I: CFD modeling. ASME Journal of Fluids Engineering. 2002;124:772-7.

[5] Davis JA, Stewart M. Predicting globe control valve performance-Part II: Experimental verification. ASME Journal of Fluids Engineering. 2002;124:77883.

[6] Qian JY, Wei L, Jin ZJ, Wang JK, Zhang H. CFD analysis on the dynamic flow characteristics of the pilot-control globe valve. Energy conversion and management. 2014;87:220-6.

[7] Rammohan S, Saseendran S, Kumaraswamy S. Numerical prediction and experimental verification of cavitation of globe type control valves. 7th International Symposium on Cavitation 2009.

[8] Chern MJ, Hsu PH, Cheng YJ, Tseng PY, Hu CM. Numerical study on cavitation occurrence in globe valve. Journal of Energy Engineering. 2012;139:25-34.

[9] Tabrizi AS, Asadi M, Xie G, Lorenzini G, Biserni C. Computational fluiddynamics-based analysis of a ball valve performance in the presence of cavitation. Journal of Engineering Thermophysics. 2014;1:27-38.

[10] Amirante R, Distaso E, Tamburrano P. Experimental and numerical analysis of cavitation in hydraulic proportional directional valves. Energy Conversion and Management. 2014;87:208-19.

[11] Jin ZJ, Gao ZX, Qian JY, Wu Z, Sunden B. A parametric study of hydrodynamic cavitation inside globe valves. Journal of Fluids Engineering. 2018;140:031208. 
[12] Chern MJ, Wang CC. Control of volumetric flow-rate of ball valve using V-port. ASME Journal of Fluids Engineering. 2004;126:471-81.

[13] Sreekala SK, Thirumalini S. Investigation on aerodynamic noise evaluation and attenuation in a globe valve using CFD analysis. The International Journal of Multiphysics. 2016;10.

[14] Palau-Salvador G, GonzĂĄlez-Altozano P, Arviza-Valverde J. Threedimensional modeling and geometrical influence on the hydraulic performance of a control valve. Journal of Fluids Engineering. 2008;130:011102.

[15] An YJ, Kim BJ, Shin BR. Numerical analysis of 3-D flow through LNG marine control valves for their advanced design. Journal of Mechanical Science and Technology. 2008;22:1998-2005.

[16] Yang Q, Zhang Z, Liu M, Hu J. Numerical simulation of fluid flow inside the valve. Procedia Engineering. 2011;23:543-50.

[17] Cao F, Wang Y, An Y, Xie Y. Three-Dimensional Flow Field in a Large-scale Gas Control Valve. International Conference on Electrical and Control Engineering. Wuhan, China: IEEE; 2010. p. 2471-4.

[18] Lafon P, Caillaud S, Devos JP, Lambert C. Aeroacoustical coupling in a ducted shallow cavity and fluid/structure effects on a steam line. Journal of Fluids and structures. 2003;18:695-713.

[19] Caridi D, Wade A, Cokljat D. Numerical Simulation of Subsonic Flow-Induced Cavity Noise. Proceedings of the Sixth International Symposium On Turbulence, Heat and Mass Transfer: Begel House Inc.; 2009.

[20] Loh C. Computation of low speed cavity noise. 42nd AIAA Aerospace Sciences Meeting and Exibit2004. p. 680.

[21] Gloerfelt X, Bogey C, Bailly C. Numerical evidence of mode switching in the flow-induced oscillations by a cavity. International Journal of Aeroacoustics. 2003;2:193-217.

[22] Rockwell D, Lin JC, Oshkai P, Reiss M, Pollack M. Shallow cavity flow tone experiments: onset of locked-on states. Journal of Fluids and Structures. 2003; 17:381-414.

[23] Fluent A. Fluent 14.0 User's Manual. ANSYS Inc, Canonsburg, PA2011. 